\title{
DATA VALIDATION OF THE DLR EARTH SENSING IMAGING SPECTROMETER DESIS
}

\author{
Uta Heiden ${ }^{2}$, Kevin Alonso Gonzalez ${ }^{1}$, Martin Bachmann $^{2}$, Kara Burch $^{3}$, Emiliano Carmona ${ }^{1}$, \\ Daniele Cerra ${ }^{1}$, Raquel de los Reyes ${ }^{1}$, Daniele Dietrich ${ }^{2}$, Uwe Knodt ${ }^{4}$, David Krutz ${ }^{5}$, Rupert Mueller \\ ${ }^{1}$, Mary Pagnutti ${ }^{3}$, Rudolf Richter ${ }^{1}$, Robert Ryan ${ }^{3}$, Ilse Sebastian ${ }^{5}$ and Mirco Tegler ${ }^{2}$
}

\author{
1 Remote Sensing Technology Institute, DLR, Oberpfaffenhofen, 82234 Weßling, Germany; \\ 2 German Remote Sensing Data Center, DLR, Oberpfaffenhofen, 82234 Weßling, Germany; \\ 3 Innovative Imaging and Research, Corp. (I2R), Building 1103, Suite 140C, Stennis Space Center, \\ 4 Strategic Services, DLR, Linder Höhe, 51147 Köln, Germany; \\ 5 Institute of Optical Sensor Systems, DLR, Rutherfordstraße 2, 12489 Berlin, Germany;
}

\begin{abstract}
Imaging spectrometry provides densely sampled and finely structured spectral information for each image pixel over large areas, enabling the characterization of materials on the Earth's surface by measuring and analyzing quantitative parameters allowing the user to identify and characterize Earth surface materials such as minerals in rocks and soils, vegetation types and stress indicators, and water constituents. The recently launched DLR Earth Sensing Imaging Spectrometer (DESIS) installed on the International Space Station (ISS) closes the long-term gap of sparsely available spaceborne imaging spectrometry data and will be part of the upcoming fleet of such new instruments in orbit. DESIS measures in the spectral range from 400 and 1000 $\mathrm{nm}$ with a spectral sampling distance of $2.55 \mathrm{~nm}$ and a Full Width Half Maximum (FWHM) of about $3.5 \mathrm{~nm}$. The various DESIS data products available for users are described with the focus on specific processing steps. A summary of the data quality results are given. The product validation studies show that top-of-atmosphere radiance, geometrically corrected, and bottom-of-atmosphere reflectance products meet the mission requirements.
\end{abstract}

Index Terms - hyperspectral remote sensing; imaging spectrometry; earth observation; DESIS; MUSES; ISS

\section{INTRODUCTION}

DLR's Earth Sensing Imaging Spectrometer (DESIS), jointly developed by the German Aerospace Center (DLR) and Teledyne Brown Engineering, is the first operating imaging spectrometer onboard the ISS [1,2]. DESIS is integrated into the Multi-User System for Earth Sensing (MUSES) platform, which provides accommodations for two large and two small hosted payloads and provides position and attitude measurements, master time, data downlink, and other core services common for each payload
[3]. DESIS records data with an exceptionally high spectral resolution of $2.55 \mathrm{~nm}$ and a spatial resolution on the ground of about $30 \mathrm{~m}$ pixel size. In addition, DESIS is opening up further special fields of application. The off-nadir capability of DESIS with $\pm 15^{\circ}$ along the track during one image strip acquisition enables investigations of multiangular characteristics of objects on Earth, providing additional target-specific signatures. Finally, DESIS can be seen as a precursor instrument for EnMAP, as it has the same detectors in the VNIR range $[4,5]$. The experience gained, especially in the laboratory calibration and commissioning phase of DESIS, will be incorporated into the EnMAP program. In the following the main outcomes of the DESIS product validation during the commissioning phase are given as described in [6]. New updates will be given at the conference.

\section{DESIS PRODUCTS}

The DESIS instrument can continuously collect data up to a maximum length of $3000 \mathrm{~km}$ on the ground. Such Earth data-takes are embedded with measurements of the dark signal before and after the acquisition. The data-take is divided into $1024 \times 1024$ pixel tiles, corresponding to $30 \times$ $30 \mathrm{~km}^{2}$ on the ground. Together with derived metadata and orbit/attitude products, the tiles are placed in a long-term archive. Data of different processing levels can be requested via web portals (see [7]). Table 1 summarizes the products a user or customer can order.

Table 1 DESIS products and user selectable processing parameters.

\begin{tabular}{l|l|l}
\hline $\begin{array}{l}\text { Product } \\
\text { Type }\end{array}$ & Description & Order parameters \\
\hline L1B & $\begin{array}{l}\text { Radiometric and sensor } \\
\text { specific corrected data. Top } \\
\text { of Atmosphere (TOA). All }\end{array}$ \\
\hline
\end{tabular}




\begin{tabular}{lll}
\hline & $\begin{array}{l}\text { metadata attached for further } \\
\text { processing }\end{array}$ & \\
\hline L1C & L1B data orthorectified and & Map Projection \\
& resampled to a specified grid & Resampling \\
& using global SRTM 1 arcsec & \\
& DEM for terrain correction & \\
& using global Landsat ETM+ & \\
& references for sensor model & \\
& refinement & \\
\hline L2A & L1C data atmospherically & Terrain \\
& corrected (reflectance) using & Correction \\
& global SRTM 1 arcsec DEM & Ozone Column \\
for topographic correction & \\
generating several masks & \\
& (water, land, cloud, & \\
shadow,...) &
\end{tabular}

A detailed algorithm description and the product specifications can be found at the DLR DESIS Official Website [7]. This website also describes how users from the scientific community can obtain DESIS data and view the License Agreement regarding the Use of the DESIS Data for Scientific Use. For commercial applications, please visit [8]. It should be noted that the use of DESIS data with spectral sampling better than $10 \mathrm{~nm}$ requires a special approval

\section{PRODUCT QUALITY AND VALIDATION}

Based on some laboratory instrument characterization the radiometric, geometric and spectral characterization of the instrument has been significantly improved by vicarious calibration using ground measurements at well known test sites and through cross-calibration with Landsat-8 and Sentinel-2 data. The following gives an overview of the data validation studies.

\section{TOP-OF-ATMOSPHERE VALIDATION AGAINST RADCALNET}

Table 2 shows the test sites and dates, which are used for Top-of-Atmosphere validation of the DESIS radiometric data which are covering a time frame of six months.

Table 2 Example of DESIS scenes of RadCalNet sites used for TOA-L validation within this study. SZA, solar zenith angle; VZA, sensor view zenith angle; RVUS, Railroad Valley, USA; GONA, Gobabeb, Namibia.

\begin{tabular}{llll}
\hline Test Site & Date & SZA & VZA \\
\hline RVUS 1 & 13 December 2018 & $64.0^{\circ}$ & $0.8^{\circ}$ \\
GONA & 4 February 2019 & $35.3^{\circ}$ & $3.9^{\circ}$ \\
RVUS 2 & 28 June 2019 & $19.0^{\circ}$ & $3.5^{\circ}$ \\
\hline
\end{tabular}

DESIS shows good overall agreement to all three RadCalNet measurements, as it lies within $10 \%$ except for atmospheric absorption features (see Figure 1). The differences between RadCalNet and DESIS, up to $\sim 525 \mathrm{~nm}$, are partially due to noise. From $\sim 525 \mathrm{~nm}$ to $\sim 650 \mathrm{~nm}$, the results are excellent, which is also due to the fact that this wavelength region has a high SNR and minimal atmospheric features. Beyond these wavelengths, the results are likely contaminated by uncertainties in water vapor and atmospheric features, even more so as small wavelength calibration errors may also amplify the atmospheric differences. Finally, for wavelengths above $\sim 800 \mathrm{~nm}$, the Etalon effect of the CMOS sensor also has an influence. In addition, discrepancies might also result from other sources including the spectral resampling steps, viewing angle and other BRDF effects, as well as slight differences within the E0 model and the actual solar irradiance.

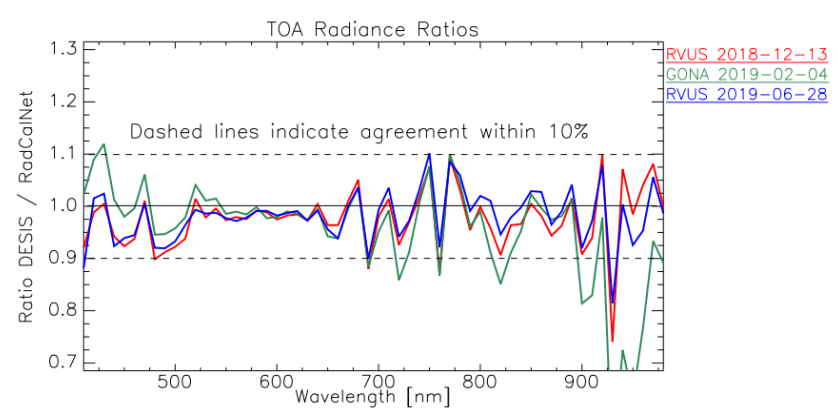

Figure 1 Ratio of mean DESIS TOA-L and corresponding RadCalNet data for all 3 sites, at RadCalNet spectral resolution.

\section{SPECTRAL CALIBRATION}

Spectral characterization of the instrument is essential, especially when the measurement data are linked to the atmospheric transmission spectra, as in L2A processing. Inaccuracies of tenths of nanometers in the spectral response can lead to strong distortions in the derived reflection spectra, especially in the region of atmospheric absorption bands. Spectral calibration of the DESIS instrument was performed in the laboratory and provided the baseline for spectral referencing of the DESIS data. Through vicarious calibration, a minor update of the spectral referencing was performed with respect to the pre-flight calibration.

For the validation of the DESIS spectral calibration, data from different calibrations and processing steps are analyzed. In Table 3, the results of this analysis are shown for the Gobabeb scene from 4 February 2019, which was found to be representative. In general, the laboratory-based spectral calibration already results in an average spectral shift of $\sim 0.5 \mathrm{~nm}$ for this wavelength range, which can be further improved when applying the spectral smile 
correction to $\sim 0.4 \mathrm{~nm}$. Using the updated vicarious in-orbit calibration, these shifts are significantly reduced to $\sim 0.2 \mathrm{~nm}$ for both processing levels.

Table 3 Spectral in-orbit validation using the Oxygen A band absorption. Shifts in [nm] calculated as average over all cross-track elements relative to the nominal band wavelengths for the Gobabeb scene. "Lab. cal" refers to the pre-launch laboratory calibration, "Vic. cal." To the vicarious in-orbit calibration

\begin{tabular}{|l|l|l|l|l|}
\hline \multirow{2}{*}{ Band } & \multicolumn{2}{|l|}{ Lab. Cal. } & \multicolumn{2}{l|}{ Vicarious Cal. } \\
\cline { 2 - 5 } & $\begin{array}{l}\text { No } \\
\text { smile } \\
\text { corr. }\end{array}$ & $\begin{array}{l}\text { Smile } \\
\text { corr. }\end{array}$ & $\begin{array}{l}\text { No smile } \\
\text { corr. }\end{array}$ & $\begin{array}{l}\text { Smile } \\
\text { corr. }\end{array}$ \\
\hline $141(\sim 760 \mathrm{~nm})$ & -052 & -046 & 0.19 & 0.26 \\
\hline $143(\sim 765 \mathrm{~nm})$ & -052 & -046 & -0.09 & -0.02 \\
\hline $146(\sim 773 \mathrm{~nm})$ & -0.53 & -0.45 & -0.37 & -0.29 \\
\hline
\end{tabular}

\section{BOTTOM-OF-ATMOSPHERE REFLECTANCE VALIDATION}

To validate the Bottom-Of-Atmosphere (BOA) reflectance, we selected spectra from RadcalNet sites, on three different RadcalNet sites: La Crau (France), Railroad Valley Playa (USA), and Gobabeb (Namibia).

The DESIS BOA surface reflectance is consistent with RadCalNet measurements with $10 \%$ relative difference for two different sites and for all wavelengths, except for the first bands $(<420 \mathrm{~nm})$ that show a difference up to $20 \%$. This relative difference agrees with the RadcalNet site variability. For an example of the relative differences in surface reflectance see Figure 2

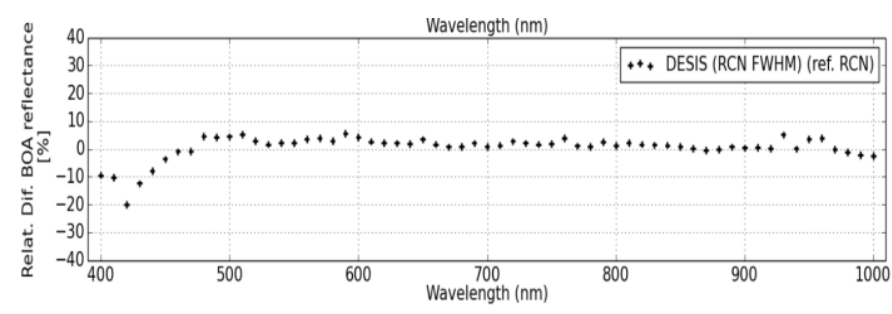

Figure 2 BOA surface reflectances at Gobabeb site (4 February 2019). DESIS spectrum at $2.5 \mathrm{~nm}$ has been convolved with RadCalNet spectral response. Relative difference $(\%)$ of surface reflectance.

\section{GEOMETRIC VALIDATION}

In order to improve the parameters of the geometric sensor model GCPs are generated for each DESIS scene using image matching employing reference images. If this on-the-fly method fails, parameters derived from statistical evaluation of a series of previous acquisitions are used. In this case, thermal influences on the MUSES/DESIS system and uncertainties in the attitude and position measurements result in worse geometric accuracy. For the assessment of the geolocation accuracy and boresight angle determination, 177 scenes were analyzed. These scenes were acquired globally with off-nadir viewing angles up to $26^{\circ}$ and solar zenith angles up to $73^{\circ}$. On average, $210 \mathrm{GCP}$ per scene were found for the improvement of the sensor model parameters and $968 \mathrm{CP}$ per scene for accuracy assessment. The achieved linear Root Mean Square Error with respect to the reference scenes based on the evaluation of individual scenes is given in Table 4 and is below one pixel size $(0.7$ pixel)

Table 4 Linear root mean square error with respect to reference scenes

\begin{tabular}{ll}
\hline RMSE x (Easting) & RMSE y (Northing) \\
\hline $21.0 \pm 5.9 \mathrm{~m}$ & $21.4 \pm 6.0 \mathrm{~m}$ \\
\hline
\end{tabular}

\section{CONCLUSIONS}

In May 2014, the German Aerospace Center (DLR) and the US company Teledyne Brown Engineering, Inc. (TBE) agreed to install and operate the imaging spectrometer DESIS on board of the International Space Station (ISS). The instrument, built by DLR, is the first of four possible camera systems that can be hosted by the MUSES platform. In August 2018, the DESIS spectrometer was integrated into MUSES, which marked the start of the commissioning phase. The DESIS on-orbit functional tests were successfully passed and the DLR-built processing systems installed at DLR and TBE are stably producing L1B, L1C and L2A products. Now, about five years since mission kick-off, the operational phase has been entered and the distribution of the data to the scientific and commercial community has begun. In this article, the main outcomes of the commissioning phase are presented, which are summarized as follows:

- Absolute radiometric calibration is well within $10 \%$ at the TOA radiance and TOA reflectance level when validated against RadCalNet .

- Spectral calibration after smile correction is typically better than $0.5 \mathrm{~nm}$, and always within $1 / 3$ of a spectral pixel.

- Geometric accuracy with respect to reference is $20 \mathrm{~m}(<1$ pixel) linear RMSE in the case that GCPs can be derived from image-to-image matching; otherwise, RMSE is 300$500 \mathrm{~m}$.

- BOA reflectance is within $<10 \%$ based on RadCalNet, Pinnacles, and Sentinel-2 comparisons 


\section{REFERENCES}

[1] Müller, R.; Avbelj, J.; Carmona, E.; Gerasch, B.; Graham, L.; Günther, B.; Heiden, U.; Kerr, G.; Knodt, U.; Krutz, D.; et al. The New Hyperspectral Sensor DESIS on the Multi-Payload Platform MUSES Installed on the ISS. Int. Arch. Photogramm. Remote Sens. Spat. Inf. Sci. 2016, 41, 461-467.

[2] Krutz, D.; Müller, R.; Knodt, U.; Günther, B.; Walter, I.; Sebastian, I.; Säuberlich, T.; Reulke, R.; Carmona, E.; Eckardt, A.; et al. The Instrument Design of the DLR Earth Sensing Imaging Spectrometer (DESIS). Sensors 2019, 19, 1622, doi:10.3390/s19071622.

[3] Perkins, R.; Galloway, P.; Miller, R.; Graham, L. Teledyne's muses mission on the ISS: Enabling flexible and reconfigurable earth observation from space. In Proceedings of the 2017 IEEE International Geoscience and Remote Sensing Symposium (IGARSS), Fort Worth, TX, USA, 2328 July 2017; pp. 1177-1180

[4] Krutz, D.; Müller, R.; Knodt, U.; Günther, B.; Walter, I.; Sebastian, I.; Säuberlich, T.; Reulke, R.; Carmona, E.; Eckardt, A.; et al. The Instrument Design of the DLR Earth Sensing Imaging Spectrometer (DESIS). Sensors 2019, 19, 1622, doi:10.3390/s19071622.

[5] Guanter, L.; Kaufmann, H.; Segl, K.; Foerster, S.; Rogass, C.; Chabrillat, S.; Kuester, T.; Hollstein, A.; Rossner, G.; Chlebek, C.; et al. The EnMAP spaceborne imaging spectroscopy mission for earth observation. Remote Sens. 2015, 7, 8830-8857

[6] Alonso, K.; Bachmann, M.; Burch, K.; Carmona, E.; Cerra, D.; de los Reyes, R.; Dietrich, D.; Heiden, U.; Hölderlin, A.; Ickes, J.; Knodt, U.; Krutz, D.; Lester, H.; Müller, R.; Pagnutti, M.; Reinartz, P.; Richter, R.; Ryan, R.; Sebastian, I.; Tegler, M. Data Products, Quality and Validation of the DLR Earth Sensing Imaging Spectrometer (DESIS). Sensors 2019, 19, 4471

[7] Heiden, U.; Müller, R. DESIS Mission. Available online: https://www.dlr.de/eoc/desktopdefault.aspx/tabid-13614 (accessed on 15 January 2020).

[8] Geospatial Solutions. Available online: https://https://tbe.com/geospatial/MUSES (accessed on 15 January 2020). 